\title{
Capital Allocation in Unit Trust and the Growth of Capital Market in Kenya
}

\author{
Robert Kipkorir Cheruiyot ${ }^{*} \quad$ Dr. Florence S Memba Dr. Tabitha M Nasieku \\ School of Human Resource Development, Jomo Kenyatta University of Agriculture and Technology, P.O BOX \\ 00200-62000, Nairobi, Kenya
}

\begin{abstract}
Unit trust schemes approach capital allocation in different ways depending on where they are in the growth life cycle and their strategic focus on customer growth. An effective capital allocation strategy consistently creates value to investors' funds and sustainable growth in the capital market. Therefore this makes capital allocation an important issue to investigate particularly in unit trusts in relation to the continuous shifting of business objectives within the capital market. This study is a useful point of reference for investors, fund managers and government agencies. This study therefore sought to establish the position of capital allocation in unit trust on the growth of capital market in Kenya. The study used explanatory non-experimental research design with the analysis being carried out using a panel data. The entire population involving all the twenty three (23) trust schemes to include all money market, equity and balanced funds managed by the schemes for the period between 2009 to year 2017. The research utilized secondary data because of the small number of unit trusts companies in the NSE and availability of the required data. Secondary data collection sheet was designed and used to collect and record all information necessary on unit trust funds from schemes annual reports, surveys and CMA publications for the period under review. Data were also analyzed using both descriptive statistic and panel multiple regression analysis by means of SPSS Version 21. Both dependent and independent variables were analyzed using panel data to determine the strength and relationships of the variables. The study revealed that Capital allocation contributed positively to the growth of capital market in Kenya. These findings were presented in the forms of a regression model. The study findings is used as a basis to recommend that the unit trust fund managers should actively evaluate the choices when allocating funds since it positively contribute to the growth of capital market. This would contribute to the realization of economic pillars in Kenya vision 2030.
\end{abstract}

Keywords: capital allocation, capital market, growth and unit trusts

DOI: $10.7176 / \mathrm{RJFA} / 10-12-01$

Publication date:June $30^{\text {th }} 2019$

\section{0: Introduction}

It is generally established that asset allocation account for a huge component of the variability in the return on a distinctive investor's portfolio. This is particularly true when the overall portfolio is invested in multiple funds and each including a number of known securities (Sharpe, 1992). The analysis of Sharpe (1992) indicates that though it is possible to try to find out a fund's exposure from a careful analysis of the securities held by the fund, other approaches however provides further information for the purpose of asset allocation. Such methods use only realized fund returns to deduce the type of exposures in the fund to the asset classes. It is also prudent to scrutinize the behavior of a manager's average exposures in relation to asset classes for a period of time. To examine these behaviors a series of style analyses can be performed, with a fixed number of months for each analysis during the period under consideration.

According to CMA (2011) the capital market continues to play a key role in mobilizing funds and enhancing economic development, the development financing necessities of the economy point to a greater demand on the capital market so as to achieve national goals. Therefore mechanism has to be placed to create proper capital market structures and mechanisms to sustain the economic, financial and commercial goals of the country.

Nyanchama (2014) noted that Kenya has a proportional and competitive advantage in the regional market where it can boost domestic capital market by position itself on regions where there is largely untapped potential for capital accumulation. Efforts must therefore be made to empower specific segments of the Kenyan capital markets that have previously not been developed concurrently with other areas of the market, and where the country has the natural strengths and potential to develop into a leading player. This will enlarge the span of the overall capital market beyond the borders of basic conventional products.

Unit trust has been considered low risk and less complicated market for investors who can invest any sum of money yet providing room for diversification. These collective investment schemes provide regular income and growth plan for most conservative investors in the market (CMA, 2010).

Wamburu and Wainaina (2014) carried out a study on the factors affecting the development of an emerging capital market with a specific focus on the Ghana stock market. The study concluded that the most significant factors impinging on the development of the Ghana stock are lack of national consciousness, lack of information 
about stock markets and generally poverty amongst its the people. This finally translates into the low figures of listed stocks, the small number of listings, poor benefaction in the market and other limitations.

It is the desire of investors to seek out diversification in their asset portfolios and considering the performance of the stock markets, many investors have sought to diversify their holdings further by investing in unit trusts. Unit trusts are attractive mainly because of the minimum risk involved as well mutual funds are professionally managed. These funds are invested in shares, bonds and real estate's (Kagunda, 2015).

Based on ones' objectives and constraints one has to specify individual asset allocation strategy, that is, one has to decide how much of one's portfolio has to be invested in each of the asset categories: cash, bonds, stock, real estate, precious metals and others (derivatives). The conventional wisdom on the asset mix is embodied in two propositions; other things being equal, an investor with greater tolerance for risk should tilt the portfolio in favour of stocks, whereas an investor with lesser tolerance for risk should tilt the portfolio in favor of bonds (Nyanchama, 2014).

\subsection{Statement of the Problem}

Ali, Lee, and Shaikh (2011), showed that an active asset allocation strategy remained a very important and dominant vehicle for investment when performance of unit trust is under consideration. In particular the study examines the pattern of asset allocation and the performance of unit trust in Malaysia by using risk-adjusted performance measures and multi-factor model from the year 2000 to 2004. Findings from multifactor model indicates that all funds of different objectives registered positive alphas attributed to the diversification and specific strategies employed by fund managers on different funds. This therefore provides a significant and positive factor that explains unit trust performance.

The specific aspect of capital allocation by the fund managers in making choices on the best investment strategy has equally drawn the attention of unit holders. This is because it determines how the particular unit trust will reward its investors. Most unit trust funds managers disclose the investment information to the public for the purpose of transparency. It is also true that unit holders will prefer those fund that promise a higher return compared with those that perform dismally. It is worth noting that there has been some growth in Unit Trust but at a slower rate than expected with few specific firms taking the lion share of the total funds. Therefore there is need to determine the specific attributes in the unit trust which operate as a inducement to attract investors consequently the growth of capital market in Kenya. It is against this background that this study seeks to fill up the gap by bringing out the contribution capital allocation in unit trust funds on the growth of capital market in Kenya.

\subsection{Specific Objectives.}

To establish the contribution of capital allocation to the growth of capital market

\subsection{Research Hypothesis.}

$\mathrm{H}_{\mathrm{O} 1}$ : There is no significant relationship between allocation of capital and the growth of capital market

\subsection{Scope of the Study.}

This study covered all the registered unit trust funds in Kenya for a period of nine years between the year 2009 and 2017. There were twenty three (23) registered and active unit trust funds in Kenya according to Capital Market Authority as at December 30, 2016. The secondary data was collected for analysis from documented sources.

\section{LITERATURE REVIEW}

\subsection{Introduction}

This part presents together theoretical and empirical literature reviews organized according to the fundamental aspects that identify the study variables. Section 2.2 is the theoretical literature, section 2.3 gives the conceptual framework and Section 2.4 discusses the empirical literature.

\subsubsection{Prospect Theory.}

Prospect theory was developed by Daniel Kahneman and Amos Tversky in 1979 as a psychologically alternative to the theory of expected utility maximization. The model is descriptive: it tries to model real-life choices, rather than optimal decisions, as normative models do. This theory describes how people make choices in situations where they have to decide between alternatives involving risk. It suggests that people evaluate a prospect on gains and losses rather than on final assets and further that they view gains and losses separately. Prospect theory can be deconstructed into four distinct processes, the editing process, the value function, probability weighting and risk attitude assessment (Cochran, 2001).

Mwenga (2004) argues that value function differs from the utility function in expected utility theory due to a reference point, which is determined by the subjective impression of individuals. According to prospect theory, 
the slope of the utility function is upward sloping for wealth levels under the reference point and downward sloping for wealth levels after the reference point. The reference point is determined by each individual as a point of comparison. For wealth levels under this reference point investors are risk seekers, that is, they are prepared to make riskier bets in order to stay above the preferred target level of wealth

One of the most significant and unique features in Kahneman and Tversky's approach to choice under uncertainty is aversion to loss realization. The behavior pattern of general disposition to sell winners too early and hold losers too long and consideration of other elements including mental accounting, regret aversion, selfcontrol, and tax considerations are consistent with this descriptive model (Shefrin and Statman, 1985).

Regret is an emotion that occurs after people make mistakes. Investors avoid regret by refusing to sell shares whose prices have gone down and willing to sell those that have appreciated. Moreover, investors tend to be more regretful about holding losing stocks too long than selling winning ones too soon (Forgel and Berry, 2006).

Prospect theory may be used to explain the irrationality that is constantly seen in financial markets that goes contrarily to the assumptions of the EMH that prices reflect the intrinsic value of securities. Investors often have an irrational preference for stocks paying high dividends as they do not mind spending the dividend income, but are not inclined to sell a few shares even when the fundamentals demand they sell since they consider shares to be their hard earned investment (Nyamute, 2016).

According to Kahneman (1979), further points out that the way economic agents subjectively frame an outcome or transaction in their mind affects the utility they expect or receive. This theory however fails to explain why people are attracted to both insurance and gambling given the levels of risks or uncertainties.

The Prospect theory draws its strength from how people make choices in situations where they have to decide between alternatives involving risk in firms. This theory provides for a non-biased perspective on the relationship between growth of capital market and the contribution in unit trusts variables employed by this study. By providing information that effects investment in unit trusts, the theory offers a neutral platform to undertake an incisive empirical analysis of this relationship within the capital market.

\subsubsection{Modern Portfolio Theory}

Markowitz (1952) developed the theory of portfolio analysis that provides the basis for scientific portfolio construction that result in an efficient portfolio. The theory provides an explanation on how to maximize portfolio expected return considering the amount of portfolio risk. It also involves minimizing risk for a specified level of expected return, by cautiously selecting the proportions of assets classes to invest in.

Essential to modern portfolio theory is the premise that investment decisions are made to achieve an optimal risk or return tradeoff from the accessible opportunities. The primary motivation of holding a portfolio instead of a solitary investment is to get the most out of return while minimizing risk. Portfolio Selection is based on the theory that investors should focus on selecting optimal portfolios as opposed to optimal assets.

According to this theory, it's achievable to create an efficient frontier of best possible portfolios capable to offer the maximum expected return for a known level of risk. The process of portfolio construction involves careful and sequential steps of security valuation, asset allocation, and portfolio optimization and performance measurement.

It may be useful to mention here that the theory of portfolio selection is a normative theory. A normative theory is one that describes a standard or norm of behavior that investors should pursue in constructing a portfolio, in contrast to a theory that is actually followed. Together MPT and asset pricing theory provide a framework to specify and measure investment risk and to develop relationships between expected asset return and risk.

MPT is a concept of diversification formed by investing in different types of assets because frequently they change in value in opposite direction. This eventually provides a collection of investment assets that has collectively lower risk than any individual asset in the market (Bhalla, 2010).

Under certain assumptions and for specific quantitative definitions of risk and return, MPT explains how to find the best possible diversification strategy. Direct test of the actual performance of professionals who often are compensated with strong incentives to outperform the market should represent the most competing evidence of market efficiency. There are a number of assumptions fundamental to this theory in view to investors' behavior and risk tolerance. The investors consider each investment option as being represented by a probability distribution of expected returns over a specified holding period. They then estimate the risk of the portfolio on the basis of variability of expected returns to maximize one period expected utility ( Brown and Reilly, 2009).

Many imaginary and sensible criticisms have been leveled against this theory with the most essential being its measurement of risk in terms of total risk while the applicable risk in investment appraisal is a systematic risk and the truth is that financial returns do not follow a Gaussian distribution or in fact any symmetric distribution, and the correlations between asset classes (Micheal, 1998). This theory recognizes the importance of maximizing the return for investors; therefore the theory is of relevance to the study. 


\subsubsection{The endogenous growth model}

The endogenous growth theory provides an explanation to the rate of growth and attributes it to the exogenous factors as described by Harrod Damar model. The theory lays a strong emphasis to different growth opportunities arising from physical capital and knowledge capital. In particular it links an increase in investment in knowledge to increase in growth and further higher savings rate.

Among the proponents of this model is Rebelo (1991), in this model focus is on the endogenously generated savings as an important variable that has the capability to foster long-run growth. It is therefore paramount to note that the policy makers should prioritize actions that have the ability to change the fundamentals to save among the general public.

This theory on growth has been discussed by many scholars in light of the growth of capital market credited to exogenous factors where one of the variables is outlined in the objective of this study. The growth theory explains that economic growth arising from mounting returns to the use of knowledge though its application is only supported by its assumptions. The theory argues that knowledge is unique from other economic goods in view of the fact that it has the possibility to grow boundlessly. Therefore this confirms that capital accumulation directly determines future growth. Policy intervention is therefore considered crucial to influence growth in the long run. This growth model, therefore, points on the role of human capital formation which positively stimulates investment on attractive options available thus complementing this study.

\subsection{The Conceptual Framework}

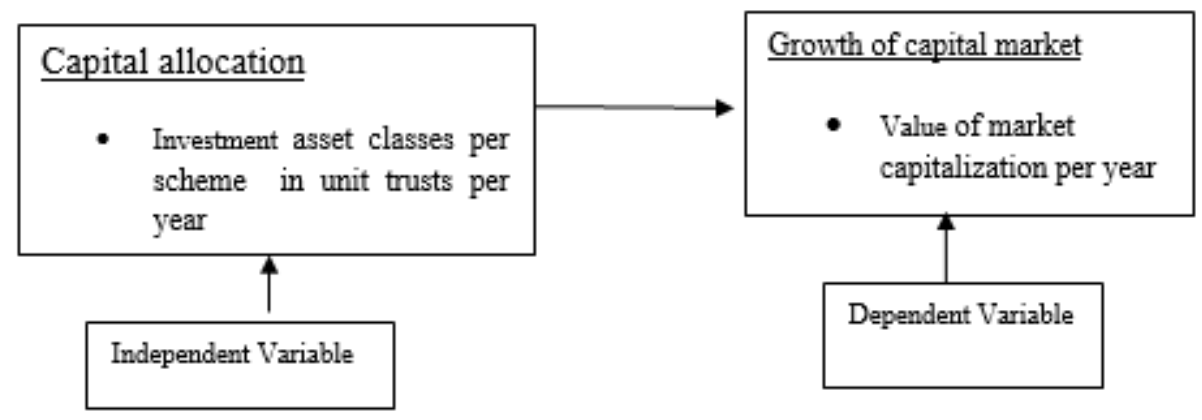

\subsection{Empirical Review}

\subsubsection{Capital Allocation}

The studies conducted by Yeap (2002) on the role of asset allocation in the styles and performance of unit trust funds in the mutual funds industry in Malaysia confirm the importance of asset allocation. The author aims to attribute the performance of unit trust funds to respective asset allocation and investment policies in their portfolios. Using generic factor model to analyze the relationships the author concludes that the factor which differentiate one fund type and its performance from another is the asset allocation policy.

Bryant (2013) examines the relationship between asset allocation and financial performance of mutual funds in Kenya. The objective of the study was to investigate whether unit trusts in Kenya have better performance compared to that of market portfolio, given their systematic risk. Jensen's standard performance measure was used to analyze the secondary data. The study found out that there is a possible relationship between asset allocation and financial performance as the study established that mutual funds that efficiently allocated their assets obtain favourable financial performance which led to more returns and better performance overall.

Kagunga (2010) did an evaluation of asset allocation by fund managers and the financial performance of unit trusts in Kenya. The study focused on one objective of evaluating the relationship between asset allocation by fund managers and the financial performance of unit trusts in Kenya. Using Jensen's standard performance measure to analyze secondary data.The study established that for unit trusts available to Kenyan investors, asset allocation can explain a significant amount of the difference in returns across time and hence a primary determinant of return performance for these trusts. The study also found out that asset allocation by fund managers and the financial performance of unit trusts in Kenya are better resolved for performance to be effective in a very great extent. The study further established that asset allocation by fund managers and the financial performance of unit trusts in Kenya is a comprehensive important measurement and mitigation method used for various organizations hence much important if effectively implemented and utilized.

Bryant ( 2013) points out two types of asset allocation strategies namely: strategic and tactical asset allocation. Strategic asset allocation refers to how portfolio funds will be divided given the portfolio manager's long-term forecasts of expected returns, variance and covariance. Tactical asset allocation on the other hand refers to how the funds are to be divided at any particular moment given the investors short-term forecasts. The 
decision determines what deviations based on current market valuations should be made from the strategic asset allocation. The process of asset allocation allows for the formation of an efficient set and this allows the investment manager to invest in those securities that form the optimal portfolio.

According to Brown and Allen (2012) study on the USA regulatory environment. There is need to have funds to disclose holdings on a quarterly basis with a 60 day lag. Prior to 2004, the frequency requirement was for semi-annual reporting (also with a 60-day lag). By disclosing all holdings, investors would be able to have information about asset allocation and would have more information to monitor whether New Zealand funds are 'true to label'. The researcher also found evidence that funds hiding their true styles may be a problem in New Zealand. They find evidence that New Zealand fund managers deviate from their stated investment objectives, with claimed equity-orientated funds providing returns that are significantly different from equity returns.

\subsubsection{Growth of Capital Market}

Capital market authority is focusing to position itself as the heart of African capital markets by improving Kenya's connectivity to global market and its competitiveness as a financial centre as well. This commitment in broadening all range of products and services available is meant to stimulate domestic development and provide the much needed gateway for international capital flows (CMA, 2016).

Capital Market Deepening and Economic Growth: Ngugi et al, (2008) in their discussion points out that when capital market grows, it brings with it an opportunity for investors to diversify unique financial asset resources for some desired expected return. They find a strong positive relationship linking capital markets, financial access and depth, suggesting that capital markets aid depth of the financial sector and improved access to finance by investors.

From the study of Bitok et al, (2014), the government of Kenya in its effort to empower the capital market for growth set out to increase the role of the private sector in the economy, diminish the weight of public enterprises on the exchequer, rationalize the operations of the public enterprise sector to widen the support of ownership and boost capital market development.

\subsection{3: Relationship between capital allocation in unit trust and the growth of Capital Market}

Concern has been raised by CMA on the low uptake of products spanning across almost all capital markets products, even with this it worth noting that the growth of collective investment schemes in the industry remains promising. Assets under Management in the CIS market have been registering significant positive growth. The assets under management have grown from Kes. 20 billion in 2013 to Kes. 57 billion as of December 2017. Out of this money market funds being the most popular asset class among fund managers, has accounted for an average of 78 per cent of the total value of portfolios (CMA, 2018).

From the World Bank report, a projected USD 4.0 trillion in yearly investment is necessary for developing countries to attain the Sustainable Development Goals (SDGs) by 2030. Considering the investment constraint, there is a greater need to develop and strengthen capital markets so as to mobilize commercial financing. The topical financial crisis has publicized that there are considerable economic effects when there is uncertainty in the financial systems. Therefore, the functioning of financial systems has received unique attention in academic literature in recent years. A well-functioning financial system allows an economy to completely exploit its growth potential, since it ensures that the best investment opportunities gets the essential funding, at the same time the inferior opportunities are equally denied capital. Therefore, capital markets aid the optimal allocation of scarce financial resources by offering a variety of financial instruments with diverse risk and return characteristics. This competitive pricing of securities and large collection of financial instruments allows investors to better allocate their funds according to their respective risk and return appetites, thus supporting economic growth (Cytonn, 2019).

\section{0: Methodology}

A research philosophy refers to how data used in the study is gathered, analyzed and used for the intended purpose which above all determines the most appropriate choice of research design. Coopers and Schindler (2011) points out that, a researcher has to make a choice is between the positivism and phenomenology research philosophies in social sciences.

This study is mainly focused on the positivist research paradigm because it is an approach that seeks facts or causes of social and business phenomena with minimal link to subjective nature of individuals.

The data collected utilized explanatory non-experimental research design framework to bring out the link between capital allocation in unit trust and the growth of capital market. According to Kerlinger (1973) an explanatory non-experimental research design is suitable when the researcher is trying to make clear how the phenomenon operates by identifying the fundamental factors that create change especially when there is no manipulation of the independent variable.

The study adopted a census approach because of the small number of unit trusts companies in the NSE. From this a target population of 23 unit trust firms listed at the NSE as at 31st December 2016 was used for data collection. The study accordingly borrowed the sentiments of (Saunders, Lewis and Thornhill 2007) who 
credited census approach as being able to enhance validity of the collected data by including certain informationrich cases.

The study accordingly adopted the use of secondary data sources which was gathered through relevant annual financial publications, surveys and reports of the unit trusts funds in Kenya. Data on the contribution of Capital allocations were collected from the relevant unit trusts firms' form 2009 to 2017. Panel data estimation technique was used considering the unique nature of this method in handling heterogeneity associated with individual firms.

The statistics obtained from the method were analyzed by means of correlation panel multiple regression analysis. To test the hypothesis panel data analysis was employed and SPSS output on test between -subject's effects on growth of capital market determined whether to accept or reject the null hypothesis.

\subsection{Model specification}

The study adopted panel data estimation model to find out the kind of association between capital allocation in unit trust and the growth of capital market. This model was used specifically to take care of multiple time periods and secondly because panel data approach gives the researcher with a big number of data points, which in turn increases accuracy for interpretation.

The framework for panel data regression used for this study took the form:

$Y_{i t}=\alpha_{i}+\beta_{1} X_{i t}+u_{i t}$

Where $u_{i t}=$ error term

$Y_{i t}=$ growth of capital market for $i^{\text {th }}$ schemes in $t^{\text {th }}$ year.

$\mathrm{X}_{\mathrm{it}}=$ representing independent variables for firm $\mathrm{i}$ in year $\mathrm{t}$,

$\beta_{1}=$ Coefficients of the independent variables,

$\mathrm{u}_{\mathrm{it}}=$ the intercept for each scheme,

$\mathrm{i}=1,2 \ldots 23$ (individual unit trust firms),

$\mathrm{t}=1,2 \ldots 9$ (time indicator).

The fixed effect model and random effect model are significant tests to estimate the parameters involved. Therefore to test the influence of capital allocation in unit trust on the growth of capital market in Kenya, the study adopted the followingequation.

$\mathrm{y}_{\text {it }}=\alpha_{\mathrm{i}}+\mathrm{X}_{\mathrm{it}} \beta 1+\mathrm{u}_{\mathrm{it}}$

Where $\mathrm{u}_{\mathrm{it}}=$ error term

$\mathrm{y}_{\mathrm{it}}=$ growth of capital market for $\mathrm{i}^{\text {th }}$ schemes in $\mathrm{t}^{\text {th }}$ year.

$\mathrm{X}_{\mathrm{it}}=$ representing independent variables for firm $\mathrm{i}$ in year $\mathrm{t}$,

$\beta_{1}=$ Coefficients of the independent variables.

\section{0: Results \& Discussion}

\section{1: Correlation analysis}

This study adopted correlation matrix for the purpose of checking the pattern of inter-relationship the variables under analysis. This was found appropriate to determine the extent of relationship between capital allocation and growth of capital market. The results are shown in Table 4.1.

Table 4.1: Correlation Matrix of the Study's Variables



The summary of analysis on Table 4.1 indicates that the correlation coefficient stood at 0.4 implying that the population data under review was free from multi-collinearity. However a higher factor would provide reasons for more tests to be conducted to rule out multi-collinearity (Gravetter and Wallnau, 2000).

\subsection{1: The Hausman Test for Model Effects Estimation}

In order to determine between fixed and random which estimation effect provided a more superior test results, Hausman test was carried out for all panel regression models. The test was led against the null hypothesis that random effect model was the most suitable model. First, a fixed-effects model was fitted to capture all temporally constant individual-level effects, and then this was compared with the random effect model. 
Table 4.2 Hausman specification test

\begin{tabular}{l|lccc}
\hline \multicolumn{5}{|c}{ Coefficients } \\
\hline & (b) fixed & (B) Random & $\begin{array}{l}\text { Difference } \\
\text { (b-B) }\end{array}$ & Sqrt (diag (vb-vB)) S.E \\
\hline Market Capital Allocation & .037654 & .038051 & -.000397 & 0.0045 \\
\hline
\end{tabular}

$\mathrm{b}=$ consistent under Ho and Ha; obtained from xtreg

$\mathrm{B}=$ inconsistent under Ha, efficient under Ho; obtained from xtreg

Test: Ho: difference in coefficients not systematic chi2 $(2)=167.34$

Prob $>$ chi $2=0.0000$

Under chosen specification, the initial hypothesis that the individual-level effects are sufficiently modeled by a random-effects model is definitely rejected.

\subsection{Regression Analysis}

Panel regression analyses for nine years between 2009 and 2017 were used to estimate the contribution of capital allocation on growth of capital market, parameter estimates were computed as shown in Table 4.3.

Table 4.3: Parameter Estimates- Capital Allocation, Time and Capital Growth Dependent Variable: Growth of Capital Market

\begin{tabular}{|c|c|c|c|c|c|c|}
\hline \multirow[t]{2}{*}{ Parameter } & \multirow[t]{2}{*}{$\mathrm{B}$} & \multirow[t]{2}{*}{ Std. Error } & \multirow[t]{2}{*}{$\mathrm{t}$} & \multirow[t]{2}{*}{ Sig. } & \multicolumn{2}{|c|}{$95 \%$ Confidence Interval } \\
\hline & & & & & Lower Bound & Upper Bound \\
\hline Intercept & 156651.7 & 66148.5 & 2.368 & .019 & 25955.5 & 287348.0 \\
\hline Capital Allocation & 12.4 & 2.2 & 5.477 & .000 & 7.9 & 16.8 \\
\hline$[$ Time $=2010]$ & -34428.8 & 68152.6 & -.505 & .614 & -169084.7 & 100227.0 \\
\hline$[$ Time $=2011]$ & -40736.0 & 68244.9 & -.597 & .551 & -175574.3 & 94102.2 \\
\hline$[$ Time $=2012]$ & -54039.1 & 68156.5 & -.793 & .429 & -188702.7 & 80624.4 \\
\hline$[$ Time $=2013]$ & -193.7 & 68320.1 & -.003 & .998 & -135180.6 & 134793.2 \\
\hline$[$ Time $=2014]$ & -37784.4 & 68159.5 & -.554 & .580 & -172453.9 & 96885.0 \\
\hline$[$ Time $=2015]$ & -48367.1 & 68229.5 & -.709 & .479 & -183175.0 & 86440.7 \\
\hline$[$ Time $=2016]$ & -18577.3 & 68194.2 & -.272 & .786 & -153315.3 & 116160.7 \\
\hline$[$ Time $=2017]$ & $0^{\mathrm{a}}$ & & & & & \\
\hline
\end{tabular}

a. This parameter is set to zero because it is redundant.

$y=\alpha_{3 t}+\beta_{3 i t} x_{3 i t}+\varepsilon$

$y=156651.7+12.4 x$.

The parameter estimates as shown in Table 4.3 indicates the contribution of capital allocation, including its standard error and confidence interval. The findings of the study reveal that for every one unit increase in capital allocation, there is subsequent increase of growth in capital market of 12.4 units at 95\% C.I $(4.9,8.0), p=0.000$. This is fairly large amount of influence on growth of capital. However, none of the coefficients of specific groups of times were significant which further reveals that time as a fixed factor has no statistically significant effect on growth of capital market.

These results agree with Fowler, Grieves, and Singleton (2010) who found in their study that, unit trusts available to New Zealand investors, asset allocation can explain a significant amount of the differences in return across time and between trusts. In particular when analyses were done across time, asset allocation accounted for about 80 per cent of the variation in actual returns. But when the analyses were done between trusts, asset allocation explains about 60 per cent of the variation in returns. From the perspective, the choice of asset allocation became an important factor in explaining returns.

These findings are also consistent with Olando (2012) who found a significant positive relationship between funds allocation strategy components and growth of wealth in SACCOs' wealth. The effect accounted for a very high variability indicating strong influence of capital allocation strategy on the growth of SACCOs' wealth.

(Bryant, 2013), undertook to study mutual funds in Kenya covering the period 2007-2011, specifically looking at how these unit trusts allocate asset and the impact of their asset allocation decision on the financial performance. The study concluded that given the desire of investors to seek out diversification in their asset portfolios and considering the performance of the stock markets, many investors sought to diversify their holdings further by investing in unit trusts. This supports this study by adding strength to the hypothesis that capital allocation plays a significant role in the growth of capital market.

\subsection{1: Test of hypothesis}

To investigate the objective, the capital market capitalization was regressed on the unit trust capitalization. To test the null hypothesis, panel data analysis was yet again used for this analysis, with independent variable being capital allocation and the dependent variable as growth in capital market in the same period. To test the null hypothesis that "there is no statistically significant relationship between capital allocation and growth of capital 
market" GLM analysis was conducted. The model produced would take the form of; $y=\alpha_{3 t}+\beta_{3 i \mathrm{t}} x_{3 i \mathrm{t}}+\boldsymbol{\varepsilon}$. Table 4.4 shows SPSS results output on test of between -subjects effects on growth of capital market.

Table 4.4: Tests of Between-Subjects Effects- Capital Allocation, Time and Capital Growth

\begin{tabular}{lrrrrr}
\hline Source & Type III Sum of Squares & df & Mean Square & F & Sig. \\
\hline Corrected Model & $1450229163929.8^{\mathrm{a}}$ & 8 & 181278645491.2 & 3.903 & .000 \\
Intercept & 323263843725.8 & 1 & 323263843725.8 & 6.960 & .009 \\
Capital Allocation & 1393195711795.5 & 1 & 1393195711795.5 & 29.995 & .000 \\
Time & 60287926213.3 & 7 & 8612560887.6 & .185 & .988 \\
Error & 7013619655796.5 & 151 & 46447812290.0 & \\
Total & 30943345492816. & 160 & & \\
Corrected Total & 8463848819726.4 & 159 & & & \\
\hline
\end{tabular}

a. $\quad$ R Squared $=.171$ (Adjusted R Square $=.121$ )

From Table 4.18, it is again evident that time was not significant predicator of growth of capital market as signified by $\mathrm{p}=0.988$ (ns). However, capital allocation was statistically significant at the .05 level $[\mathrm{F}(1,151)$ $=29.995, \mathrm{p}=0.000]$. Agreed, that calculated $\mathrm{p}$-value $=0.000$ being less than the priori significant level of 0.05 , the null hypothesis was rejected at the 0.05 level of significance. This implies that there was enough statistical evidence to indicate that the more the unit trusts, the more the capital market. Therefore, it was concluded that there is significant relationship between capital allocation and growth of capital market, with rise in capital allocation associated to increase in growth of capital market in Kenya and vice versa.

\subsection{2: Evaluating Contribution of capital allocation}

The study sought to investigate the level of contribution of capital allocation factored in the model in the prediction of the dependent variable. This was shown by coefficients values in Table 4.5:

Table 4.5: Coefficient Output: Unit Trust Funds on Growth of Capital Market

\begin{tabular}{|c|c|c|c|c|c|}
\hline \multirow[t]{2}{*}{ Model } & \multicolumn{2}{|c|}{ Unstandardized Coefficients } & \multirow{2}{*}{$\frac{\text { Standardized Coefficients }}{\text { Beta }}$} & \multirow[t]{2}{*}{$\mathrm{t}$} & \multirow[t]{2}{*}{ Sig. } \\
\hline & $\mathrm{B}$ & Std. Error & & & \\
\hline (Constant) & 628223.9 & 113577.3 & & 5.531 & .000 \\
\hline Capital Allocations & 20.0 & 3.340 & .662 & 5.991 & .000 \\
\hline
\end{tabular}

a. Dependent Variable: Growth of Capital Market

From the coefficient output table it is evident that capital allocation in unit trust funds had statistically significant influence on growth of capital market in Kenya. The capital allocation had strong beta coefficient of $0.662(\mathrm{p}<.05)$, implying that it made a unique contribution to explaining the dependent variable during the period. This means that a one standard deviation improvement in capital allocation leads to a 0.662 standard deviation increase in growth of capital market, keeping any other variable that may have an influence constant.

\section{0: Conclusion and Recommendation 5.1 Conclusion}

The analysis of the capital allocation in unit trust on the growth of capital market shows the capital allocation had the positive and significant influence on enhancing growth of capital market. In view of the findings, the study concludes that capital allocation of funds in collective investment schemes requires sufficient attention by fund managers to draw investment through various innovative options available in the capital market.

\section{2: Recommendations}

The study recommends that unit trust funds should embrace prudent and popular capital allocation techniques that provide value to investors' funds. This would be through thorough investment appraisals by fund managers to yield fair returns. Capital allocation being one of the many contributors to the growth of capital market can play its role well if focus is placed to secure profitable options only. This would in turn attract funds to the schemes consequently leading to the growth of capital market.

\section{3: Suggestion for Further Research}

The study was carried out in Kenya where unit trust industry is still growing. The applicability of the results of the study may be limited to the area of study due to the nature of the industry; however this can be improved if further comparative studies can be done across capital markets with different strengths. Future research is equally necessary to investigate the relationship between investor education and investment in different asset classes in unit trust funds.

\section{REFERENCES}

Ali, A., Huson, J., Lee L., \& Shaikh, M. (2011). An investigation on asset allocation and performance measurement for unit trust funds in Malaysia using multifactor model: a post crisis period analysis. 
International Journal of Managerial and Financial Accounting. 3. 22-31. 10.1504/IJMFA.2011.038362.

Bitok, S., Bitok, J., \& Kosgei, N. (2014). Factors Influencing the Development of Capital Markets in a Developing Economy: A Case Study of Nairobi Securities Exchange in Kenya.

Brown, C., Keith, G., \& Reilly. K. F. (2009). "Investment analysis and portfolio management" 6th edition, Druden Press.

Brown, K., \& Allen, G. (2012). Exposure Draft: KiwiSaver (Periodic Disclosure) Regulations Exposure Draft to Ministry of Economic Development, Brown, K. C., \& Reilly, F. K. (2009). Investment Analysis and Portfolio management.

Bryant, B. D. (2013). Relationship between Asset Allocation and Financcial Performance of Mutual Funds in Kenya. Journal of Chemical Information and Modeling, 53(9), 1689-1699. http://doi.org/10.1017/CBO9781107415324.004

CMA. (2010). The CMA Quarterly Capital Markets Statistical Bulletin (Q3).

CMA. (2011). Proposed Intervention Measures Targeted at Boosting the Development of Islamic Capital Markets in Kenya, (December).

Cochran, A, (2001). Prospect Theory \& Customer Choice

Cooper, D., \& Schindler, S. (2014). Business Research Methods. New York: McGraw-Hill Irwin

Cytonn Research (2019). Cytonn Monthly, April Report

Fogel, S. O. \& Berry, T. (2006). The Disposition Effect and Individual Investor Decisions: The Roles of Regret and Counterfactual Alternatives. The Journal of Behavioural Finance, 7(2), 107-116.

Kagunga, P. K. (2010). A Comparison of Performance Between Unit Trusts and a Market Portfolio of Shares At Nairobi Stock Exchange . (Unpublished MBA Project). Nairobi University

Kagunda, T. (2015). Asset Allocation by Fund Managers and The Financial Performance of Unit Trusts in Kenya. (Unpublished MBA Project). Nairobi University

Kahneman, D., \& Tversky, A. (1979). Prospect theory: An analysis of decision under risk. Econometrica, 47, 263-291.

Kerlinger, F.N. (1973). Foundation of Behavioural Research. New York. Holt. Rinehand and Hinston.

Mwenga, Mary. (2004). Investors Attitudes towards Investment in Financial Securities. (Unpublished MBA Project). Kenyatta University

Ngugi, R., Amanja, D., \& Maana, I, (2009). Capital market, financial deepening and economic growth in Kenya. Available at: www.csae.ox.ac.ukconference

Nyamute Winnie (2016). Investor Behaviour, Investor Demographic Characteristics, Investment Style and Individual Investor Portfolio Performance at the Nairobi Securities Exchange Unpublished PhD Thesis, Nairobi: Jomo Kenyatta University of Agriculture and Technology.

Nyanchama, O. P. (2014). Determinants of Financial Performance of Unit Trusts in Kenya, (October).

Olando C. O. (2012). Financial Practice as a Determinant of Growth of Savings and Credit Co - Operative Societies' Wealth. International Journal of Business and Social Science Vol. 3 No. 24 [Special Issue December 2012

Rebelo, S. (1991). "Long-Run Policy Analysis and Long-Run Growth", Journal of Political Economy, 99.

Ross Fowler, Robin Grieves, J. Clay Singleton, (2010) "New Zealand unit trust disclosure: asset allocation, style analysis, and return attribution", Pacific Accounting Review, Vol. 22 Issue: 1, pp.4-21, https://doi.org/10.1108/01140581011034191

Sharpe, W.F (1992). Asset allocation Management style and performance measurement, The Journal of Portfolio Management Winter 1992, 18 (2) 7-19; DOI: https://doi.org/10.3905/jpm.1992.409394

Shefrin, H., \& Statman, M. (1985). The Disposition to Sell Winners Too Early and Ride Losers Too Long: Theory and Evidence, Journal of Finance, 40, 777-790.

Wamburu, K. K. \& Wainaina,G. (2014). Determinants of Stock Market Development in Kenya: An Error Correction Model Approach. European Journal of BusinessManagement, 1 (11), 230-244.

Yeap, L. W. (2002) Does Asset Allocation explain the styles and performance of Unit Trust Funds: A style analysis with evidence from Malaysia. Journal of Malaysian Studies. 2002, Vol. 20 Issue 2, p1-32. 